\title{
AVANÇOS E DESAFIOS DA EXPANSÃO DOS CURSOS DE LICENCIATURAS NO INSTITUTO FEDERAL DO AMAPÁ NO PERÍODO DE 2011 - 2019
}

\author{
Adriana Valeria Barreto de Araujo $^{1}$, Liliane Barreira Sanchez ${ }^{2}$ \\ ${ }^{1}$ Mestre em Ciências pela Universidade Federal Rural do Rio de Janeiro - UFRRJ. Atua como Pedagoga no Instituto \\ Federal de Educação, Ciência e Tecnologia do Amapá - IFAP/campus Macapá. ORCID iD: https://orcid.org/0000-0002- \\ 8714-9566. E-mail: adrivaleriaa@gmail.com \\ ${ }^{2}$ Doutora em Educação pela Universidade do Estado do Rio de Janeiro - UERJ. Professora Associada na Universidade \\ Federal Rural do Rio de Janeiro - UFRRJ. ORCID iD: https://orcid.org/0000-0002-3250-2940. E-mail: \\ lilianesanchez@gmail.com
}

\section{RESUMO}

Este estudo analisa a participação do Instituto Federal de Educação, Ciência e Tecnologia do Amapá (IFAP) na expansão dos cursos de licenciaturas no contexto amapaense no período de 2011 a 2019. Trata-se de uma pesquisa de caráter quanti - qualitativo, ancorada na análise de referenciais teóricos e de documentos, com dados estatísticos no Sistema Unificado de Administração Pública (SUAP/IFAP) e entrevistas realizadas com estudantes, professores e gestores da Instituição. O objetivo é apontar os avanços e os desafios desse processo, relacionados ao contexto em que se inserem. Os resultados demonstraram que o IFAP desempenha importante participação na expansão da oferta de cursos de formação de professores no Estado do Amapá, pois, em oito anos, houve um expressivo crescimento no número/vagas de matrículas, contribuindo para o acesso ao Ensino Superior e consequente elevação da escolaridade, além de contribuir na superação da carência de docentes na região norte e no País.

Palavras-chave: Expansão. Formação de professores. Institutos Federais. Educação Profissional.

\section{CHALLENGES OF EXPANSION OF LICENSE COURSES AT THE FEDERAL INSTITUTE OF AMAPÁ IN THE PERIOD OF $2011-2019$}

\section{ABSTRACT}

This study analyzes the participation of the Federal Institute of Education, Science and Technology of Amapá (IFAP) in the expansion of undergraduate courses in the context of Amapá in the period from 2011 to 2019. It is a quantitative and qualitative research, anchored in the analysis theoretical references and documents, with statistical data in the Unified Public Administration System (SUAP / IFAP) and interviews with students, teachers and managers of the Institution. The objective is to point out the advances and challenges of this process, related to the context in which they operate. The results showed that IFAP plays an important role in expanding the offer of teacher training courses in the State of Amapá, since, in eight years, there has been an expressive growth in the number / enrollment places, contributing to the access to Higher Education and consequent schooling, in addition to contributing to overcoming the shortage of teachers in the northern region and in the country.

Keywords: Expansion. Teacher training. Federal Institutes. Professional Education.

\section{DESAFÍOS DE EXPANSIÓN DE CURSOS DE LICENCIA EN EL INSTITUTO FEDERAL DE AMAPÁ EN EL PERÍODO 2011-2019}

\section{RESUMEN}

Este estudio analiza la participación del Instituto Federal de Educación, Ciencia y Tecnología de Amapá (IFAP) en la expansión de los cursos de pregrado en el contexto de Amapá en el período de 2011 a 2019. Es una investigación cuantitativa y cualitativa, anclada en el análisis. referencias teóricas y documentos, con datos estadísticos en el Sistema Unificado de Administración Pública (SUAP / IFAP) y entrevistas con estu- 
diantes, docentes y directivos de la Institución. El objetivo es señalar los avances y desafíos de este proceso, relacionados con el contexto en el que operan. Los resultados mostraron que IFAP juega un papel importante en la expansión de la oferta de cursos de capacitación docente en el estado de Amapá, ya que, en ocho años, ha habido un crecimiento expresivo en el número / lugares de inscripción, contribuyendo al acceso a la educación superior y consecuente escolarización, además de contribuir a superar la escasez de docentes en la región norte y en el país.

Palabras Clave: Expansión. Formación del profesorado. Institutos federales. Educación profesional.

\section{INTRODUÇÃO}

As discussões acerca da expansão da Educação Superior inserem-se no âmbito das transformações políticas, sociais e históricas ocorridas no cenário mundial, que motivaram no Brasil uma série de reformas econômicas em diversas áreas, iniciadas nos anos de 1990. Tais mudanças objetivaram adequar o Estado brasileiro aos imperativos da reestruturação capitalista, que produziram alterações no papel da Escola e culminaram em reformas no campo educacional, de modo particular, na Reforma da Educação Superior e da Educação Profissional e Tecnológica.

O período compreendido entre as décadas de 1990 e 2002 foi marcado pelo fortalecimento e predomínio das matrículas em Instituições de Ensino Superior (IES) do setor privado. Segundo Sguissardi (2011), em 2002, o número de matrículas no subsistema privado de Ensino Superior era de $69,8 \%$ e a quantidade de instituições de Ensino Superior deste segmento representavam $88,1 \%$ do total geral em relação às públicas. Este cenário começou a apresentar sinais de mudanças a partir de 2008, com o esforço do governo brasileiro em retomar os investimentos nas Instituições Federais de Ensino Superior, mediante a destinação de recursos públicos para a ampliação e reestruturação das Universidades Federais (REUNI) e para a ampliação e interiorização da Rede Federal de Educação Profissional, Científica e Tecnológica (RFEPCT).

Os Institutos Federais de Educação, Ciência e Tecnologia (IFs) são instituições de ensino criadas por meio da Lei no 11.892/2008, provenientes da reestruturação das antigas Escolas Técnicas e Agrotécnicas Federais, CEFETs e Escolas Técnicas vinculadas às Universidades Federais. Todo este conjunto de Instituições compõem a Rede Federal, que atualmente possui unidades instaladas em todo o território Nacional. Os IFs correspondem a 90\% da RFEPCT e congregam 581 do total de 644 campi (BRASIL,
2016). A inserção da Educação Superior nos IFs ocorreu em razão deles serem equiparados às Universidades, admitindo as mesmas diretrizes em termos de mecanismos reguladores e avaliadores, bem como autonomia didáticopedagógica e administrativa para criar e extinguir cursos.

Lima (2016) destaca que a oferta de cursos de licenciatura nessas instituições, acompanhada por sua expansão pelo território brasileiro, faz parte das políticas de expansão da educação superior, incluindo as políticas específicas voltadas para a formação de professores, iniciadas durante o governo do então presidente Lula (2003 - 2010). De acordo com Lima e Silva (2011), a justificativa para esta oferta formativa se respalda na escassez de professores, que é um problema que afeta todas as regiões do País, sobretudo nas áreas das ciências da Natureza e da matemática, como também no próprio campo da Educação Profissional.

Deste modo, este artigo tem como objetivo central analisar os avanços e desafios contidos no processo de expansão dos cursos de licenciaturas do Instituto Federal de Educação, Ciência e Tecnologia do Amapá (IFAP), no período de 2011 a 2019, e as particularidades que o caracterizam. Para tanto, utilizou-se como aparato metodológico a pesquisa qualitativa, com consulta documental e bibliográfica, pesquisas em dados obtidos no sistema SUAP/IFAP, além de entrevistas com alunos, docentes e gestores pedagógicos da Instituição.

Ressalta-se a relevância sócio educacional deste trabalho, especialmente porque, em 2018, os IFs completaram uma década de criação, incorporando como uma de suas responsabilidades a oferta de cursos de formação de professores, que consiste em um desafio para essas instituições que historicamente não tem a Educação Superior como foco de atuação principal. Posto isso, espera-se que este artigo contribua com as discussões sobre as políticas de expansão e interiorização da Rede Federal de 
Educação Profissional, bem como com análises sobre as particularidades da oferta de formação de professores nos Institutos Federais.

\section{FORMAÇÃO DE PROFESSORES NO BRASIL E A INSERÇÃO DOS CURSOS DE LICENCIATURAS NA REDE FEDERAL DE EDUCAÇÃO PROFISSIONAL, CIENTÍFICA E TECNOLÓGICA}

Segundo Tanuri (2000), as primeiras iniciativas de formação de professores no Brasil surgiram no século XIX, com a criação das primeiras Escolas Normais destinadas à formação de docentes para o ensino primário. O currículo dessas escolas era bastante elementar, abrangendo conhecimentos das quatro operações matemáticas, leitura e escrita e princípios da conduta moral disciplinar. Não havia uma ênfase particular nos conhecimentos da formação didático-pedagógica, dado o baixo nível de qualificação dos mestres e as insuficientes condições estruturais com que essas instituições funcionavam, o que acarretava em uma preparação com pouca ou nenhuma consistência formativa. (TANURI, 2000).

Um novo padrão de ensino foi fixado nas Escolas Normais a partir da Reforma da Instrução Pública do Estado de São Paulo, em 1890, com destaque para o enriquecimento dos conteúdos curriculares já ministrados e maior ênfase nos exercícios práticos de ensino. Contudo, tais meIhorias não representaram avanços muito significativos e o desejo por mudanças se ampliou na década de 1930. Saviani (2009) considera a criação dos Institutos de Educação, em 1932, e a criação dos cursos de licenciatura e pedagogia, em 1939, como dois importantes marcos para a implantação e consolidação dos cursos de formação de professores no Brasil. Uma vez que estes foram pensados e organizados de maneira a incorporar as exigências de uma proposta pedagógica que valorizasse o conhecimento de caráter científico, aliando-o ao desenvolvimento do ensino e da pesquisa.

Ressalta-se que, desde a sua criação, os cursos de licenciatura tiveram poucas alterações consistentes em relação a sua estrutura formativa inicial. Exemplo disso é o modelo $3+1$, que tem como característica o ensino centrado na racionalidade técnica e que ainda hoje se mantém na tessitura curricular das licenciaturas. Isso se dá em muito pela descontinuidade das políticas governamentais voltadas à educação e pelo descompromisso histórico do Estado com a profissão docente. Segundo Gatti (2013), as teorias sociais geralmente atribuem a ocorrência de mudanças institucionais profundas a fatores que geram uma crise no âmbito conjuntural ou no recorte específico societário em que elas se inserem. Desta forma, a autora defende mudanças radicais na formação ofertada nos cursos de licenciatura, pois os mesmos não podem ficar à margem das transformações socioculturais e históricas ocorridas na atualidade.

Embora as universidades sejam o lócus tradicional de oferta do Ensino Superior e dos cursos de licenciatura, desde a década de 1960, tendo em vista o rápido desenvolvimento industrial, o Ministério da Educação (MEC) autorizou a oferta de cursos de engenharia ${ }^{1}$ por Instituições de Ensino Superior (IES) não universitárias. No entanto, Mancebo e Silva Jr. (2015) afirmam que os Organismos Internacionais (OI), dentre os quais, o Banco Mundial (BM) é um dos maiores incentivadores da criação de espaços diversificados para a oferta do ensino superior, com a alegação de que os cursos ofertados em outros espaços seriam mais "flexíveis" e de menor custo que os universitários ditos "tradicionais" (OTRANTO, 2011, p.12).

Nesse contexto, os Institutos Federais ganham particular atenção por apresentarem uma estrutura de ensino ampliada e diversificada, atuando na oferta da Educação Básica e Superior, em que, nesse último, se insere a oferta de cursos de licenciatura. Ressalta-se que ao longo da trajetória da Rede Federal de Educação Profissional, a possibilidade de oferta de cursos de licenciatura esteve presente na pauta de discussões do governo, dada a urgente necessidade de resolver algumas demandas estruturais da sociedade brasileira, tais como a carência de professores que atinge a rede pública de ensino do País, que é um dos fatores que impede a universalização do Ensino Médio.

As primeiras experiências com a formação de professores na Rede Federal surgiram na década de 1970, com a finalidade de suprir a carência de docentes devidamente formados para atuarem no campo da Educação Profissional.

\footnotetext{
${ }^{1}$ O Parecer no 60/63, do Conselho Federal de Educação (CFE), aprovou a proposta de criação de cursos de engenharia de curta duração, dois anos depois, o Parecer no 25/65, do CFE, detalhou as características do curso e determinou seu currículo mínimo. Sugeriu, ainda, que esses cursos "não deveriam ser criados fora dos meios industriais de significação apreciável". As IES que já ofereciam os clássicos cursos de engenharia poderiam, da mesma forma, criar os cursos de engenharia de operação, com três anos de duração em lugar dos tradicionais cinco anos. (NEVES. 2003. P. 29) Diversificação do Sistema de Educação Terciária: um desafio para o Brasil. Tempo Social - USP. Abril 2003.
} 
Em 1978, a transformação das Escolas Técnicas Federais de Minas Gerais, Rio de Janeiro e Paraná em Centros Federais de Educação Tecnológica (CEFET), trouxeram como um de seus objetivos a oferta de licenciaturas plenas e curtas para o então $2^{\circ} \mathrm{grau}^{2}$ e para a formação de tecnólogos (BRASIL, 1978, Art. 2ㅇ). Estava prevista também a formação de docentes para atuar no Ensino Técnico, através dos denominados "Esquema I e Esquema II", visando colaborar na formação de professores quando se tratasse de Educação Profissional.

O Esquema I destinava-se aos portadores de diploma de nível superior, sujeitos à complementação pedagógica e o Esquema II, aos portadores de diploma de técnico industrial de nível médio, para os quais, além das disciplinas integrantes do Esquema I, se fazia necessário cursar disciplinas de conteúdo técnico específico. Ressalta-se que o problema da escassez de mestres de ofícios e profissionais qualificados para atuar no ensino profissionalizante já havia sido percebida desde de 1909, com a criação das Escolas de Aprendizes e Artífices, sendo, portanto, uma carência histórica no cenário da educação brasileira.

No decorrer da década de 1990, outras Escolas Técnicas Federais foram se transformando em CEFET, com a responsabilidade de ministrar cursos de formação de professores, uma vez que já possuíam a autonomia para a "criação de cursos e ampliação de vagas nos níveis básico, técnico e tecnológico da Educação Profissional" (BRASIL, 1997, Art. 80). Em 2007, um ano antes da publicação da lei de criação dos Institutos Federais, o Plano de Desenvolvimento da Educação (PDE) assegurou a oferta das licenciaturas nos IFs, especialmente nas áreas de Química, Física, Biologia e Matemática, entre os demais níveis e modalidades de ensino a serem ofertados por essas instituições.

Alves (2009) salienta que um dos aspectos para a implantação dos cursos foi o fato de o MEC solicitar dos Institutos, soluções imediatas, para contribuir com a diminuição do déficit de professores das áreas exatas na Educação Básica. Logo, houve e há uma expectativa de que, com o aumento de cursos de licenciatura nos IFs, ocorra um aumento do número de professores em todo o país, de forma a remediar a necessidade urgente de docentes para a educação básica e profissional.
Em face disto, em 2008, a oferta de cursos de licenciatura nos IFs foi garantida na lei no 11.892, estabelecendo o quantitativo de no mínimo $20 \%$ das suas vagas para a oferta de cursos de formação de professores (licenciaturas), bem como para programas especiais de formação pedagógica com a finalidade de formar docentes para a educação básica, sobretudo nas áreas de ciências da natureza e matemática e para a educação profissional (BRASIL, 2008).

Em relação à formação de professores para a Educação Profissional, Machado (2008) chama atenção para a necessidade de definição sobre a forma como deve ocorrer a formação do professor deste campo de atuação. Para a autora, ainda são poucas as iniciativas de cursos de licenciatura voltados para o magistério na Educação Profissional e, embora existam formas de ofertas diversificadas, essas iniciativas são muito reduzidas em relação ao potencial da demanda e nem sempre atendem a todos os perfis de entrada dos candidatos. Pois são ofertas constituídas por programas especiais de formação pedagógica, cursos de pós-graduação, formação em serviço e formação à distância, dentre outros. (MACHADO, 2008, p.14).

$A$ atuação do professor nos IFs é cercada de especificidades que requerem uma ampla formação crítico-reflexiva acerca dos diferentes níveis e modalidades que são ofertados na estrutura dessas instituições (Ensino técnico, PROEJA, cursos superiores de tecnologia e licenciatura). De maneira que torna ainda mais complexo o trabalho docente desenvolvido nos cursos de licenciatura, pois exige do professor maior versatilidade para lidar com planejamentos e estratégias metodológicas voltadas a níveis de ensino e a públicos diversos.

Diante de tais desafios, foram organizados eventos em âmbito nacional com a finalidade de discutir sobre as demandas que motivaram a oferta da formação de professores na Rede Federal, a fim de construir uma identidade para os cursos de licenciaturas nessas instituições. Dentre esses eventos, destacam-se a realização do "I Seminário Nacional das Licenciaturas dos Institutos Federais" (SENALIF), em maio de 2010, na cidade de Ouro Preto/MG, organizado pelo Instituto Federal de Minas Gerais (IFMG) e o "I Fórum Nacional das Licenciaturas dos Institutos Federais (FONALIFES): Em busca de uma identidade", realizado pelo Instituto Federal do Rio Grande do Norte (IFRN). Esses dois eventos são considerados os

\footnotetext{
${ }^{2}$ Atual Ensino Médio.
} 
primeiros momentos de discussão nacional sobre as licenciaturas nessas instituições.

A partir das discussões fomentadas no FONALIFES foram construídas propostas para os cursos de formação docente em nível de licenciatura nos IFs, as quais resultaram em um documento chamado 'Carta de Natal', que apresentaram proposições para melhorias e diferenciais para a definição dos cursos de licenciatura ofertados pelos IFs. Para tanto, foram levados em consideração aspectos referentes à infraestrutura, gestão, formação de formadores e questões pedagógicas, cujas dimensões foram entendidas como imprescindíveis para a melhoria e para a superação das dificuldades historicamente enfrentadas no cotidiano dos cursos de formação docente. O propósito de consolidar nos IFs a formação de professores é entendida como uma das medidas para ampliar o acesso à educação superior e contribuir para a diminuição da escassez de professores.

Contudo, desde o ano de 2016 essas instituições de ensino vivenciam um cenário de incertezas e retrocessos, provocados pelos cortes de recursos financeiros e redução nos investimentos, que comprometem tanto 0 funcionamento, quanto à expansão das mesmas. A mudança para o atual governo ${ }^{3}$ tornou mais grave este quadro, visto que as reformas de caráter neoliberal que estão sendo adotadas para a educação brasileira e, particularmente para os IFs, visam enfraquecer as ações já desenvolvidas e, consequentemente, impactam no acesso, na permanência e no êxito dos estudantes. A exemplo disso, destaca-se o Projeto de Lei no $11.279 / 2019$, cujo teor prevê mudanças na estrutura da Rede, alterando a lei dos institutos e ainda desobriga os IFs de ofertar cursos de licenciatura, priorizando as vagas para os cursos técnicos em nível médio. $O$ que gera desconfiança no meio Educacional é o fato do referido Projeto de lei ter sido encaminhado no final de 2018 ao Congresso Nacional, sem passar antes por debates com a sociedade e a comunidade escolar.

Portanto, consideramos necessário e imprescindível provocar o debate coletivo com a comunidade escolar e acadêmica, bem como com os representantes políticos que atuam no cenário nacional acerca da importância de manter os IFs como lócus diferenciado de formação, em razão do potencial formativo que essas instituições

\footnotetext{
${ }^{3}$ O Governo Jair Messias Bolsonaro teve início no dia 1ำ de janeiro de 2019 e está previsto para terminar no dia 31 de dezembro de 2022.
}

possuem e da sua contribuição social para o Brasil.

\section{RESULTADOS E DISCUSSÃO: A EXPANSÃO DOS CURSOS LICENCIATURAS NO IFAP NO PERÍODO DE 2011 A 2019 E O PERFIL DA OFERTA}

No período anterior à instalação do IFAP no Estado do Amapá, havia apenas duas Instituições Públicas de Ensino Superior: a Universidade Federal do Amapá (UNIFAP) e a Universidade do Estado do Amapá (UEAP), ambas atuando com a oferta de cursos de Licenciatura, além de cursos de bacharelado. Segundo informações coletadas no Plano de Desenvolvimento Institucional (PDI-(2019-2023) da instituição, o IFAP tem sua origem vinculada a criação da Escola Técnica Federal do Amapá (ETFAP), instituída pela Lei no 11.534, de 25 de outubro de 2007, como entidade de natureza autárquica, ligada ao Ministério da Educação (MEC). A Escola Técnica Federal do Amapá (ETFAP) foi implantada pelo Centro Federal de Educação Tecnológica do Pará (CEFET/PA), por meio da Portaria MEC no 1.067, de 13 de novembro de 2007.

Em 2008, com a publicação da Lei no 11.892, a ETFAP foi transformada em Instituto Federal de Educação, Ciência e Tecnologia do Amapá, com natureza jurídica de autarquia, detentora de autonomia administrativa, patrimonial, financeira, didático-pedagógica e disciplinar. No segundo semestre de 2010, primeiro ano de sua atuação, o IFAP iniciou suas atividades na área de Ensino Técnico de Nível Médio, em dois campi: campus Macapá e campus Laranjal do Jari, com os cursos na modalidade Subsequente, a saber, Técnicos em Informática e Edificações (campus Macapá) e Técnico em Secretariado e Técnico em Informática (campus Laranjal do Jari).

A partir de 2011, começaram a ser ofertados os demais cursos de Ensino Técnico de Nível Médio nas modalidades Integrado, Subsequente e Educação de Jovens e Adultos (PROEJA), cursos superiores de Licenciaturas e de Tecnologia, Pós-Graduação Lato Sensu e Stricto Sensu e Formação Inicial e Continuada (FIC) e em 2013, como parte do plano de expansão III da Rede Federal de Educação Profissional, Científica e Tecnológica, o Instituto foi contemplado com dois campi: Santana e Porto Grande. Neste mesmo ano, iniciou-se o processo de implantação do campus Avançado Oiapoque, no município do mesmo nome, vinculado à estrutura do campus 
Macapá e a implantação do Centro de Referência de Pedra Branca do Amapari, vinculado ao campus Porto Grande.

Ressalta-se que atualmente o IFAP possui seis campi distribuídos pelos municípios do Estado do Amapá, desses, apenas os campi Macapá e Laranjal do Jari ofertam cursos de formação de professores. A partir da consulta documental realizada nos PPCs e no sistema
SUAP/IFAP, foi possível observar um significativo crescimento na oferta dos cursos de licenciatura (presencial) no período compreendido entre os anos de 2011 e 2019, sobretudo no campus Macapá, conforme demonstrado nas tabelas 1 e 2.

Tabela 1. Licenciaturas presenciais ofertadas pelo IFAP - ANO: 2011

\begin{tabular}{|c|c|c|c|c|}
\hline Ord & Campus & Cursos & Modalidade & Quant. Turmas \\
\hline \multirow{3}{*}{01} & & Lic. em Informática & Presencial & \\
\hline & Macapá & & & 01 \\
\hline & & $\begin{array}{l}\text { Lic. em } \\
\text { Química }\end{array}$ & Presencial & 01 \\
\hline 02 & Laranjal do Jari & $\begin{array}{l}\text { Lic. Em } \\
\text { Biologia }\end{array}$ & Presencial & 01 \\
\hline
\end{tabular}

TOTAL DE CURSOS: 03 cursos de licenciatura

Total de turmas: 03 turmas

Fonte: SUAP/IFAP

Tabela 2. Licenciaturas presenciais ofertadas pelo IFAP - ANO: 2019

$\begin{array}{llll}\text { Ord Campus } & \text { Cursos Quant. Turmas }\end{array}$

\begin{tabular}{|c|c|c|c|c|}
\hline 01 & & Lic. em Informática & Presencial & 04 \\
\hline 02 & & Lic. em Química & Presencial & 04 \\
\hline 03 & & Lic. em Matemática & Presencial & 03 \\
\hline 04 & & Lic. em Física & Presencial & 02 \\
\hline 05 & Macapá & Lic. em Letras & Presencial & 02 \\
\hline 06 & Laranjal do Jari & Lic. em Biologia & Presencial & 02 \\
\hline
\end{tabular}

TOTAL DE CURSOS: 06 cursos de licenciatura

Total de turmas: 17 turmas

Fonte: SUAP/IFAP

A partir dos dados organizados nas duas tabelas, é possível constatar uma crescente expansão do número de cursos e turmas, considerando o interstício dessa pesquisa. Em 2011, havia apenas 3 cursos de licenciatura e 3 turmas nos dois campi que atuam com esse tipo de oferta. Já em 2019, esse número saltou para 06 cursos de licenciatura e 17 turmas ofertantes. Em termos percentuais, pode-se dizer que houve um crescimento de mais de $100 \%$, considerando a oferta de cursos e turmas. O campus Macapá é a unidade que apresenta o maior índice de crescimento, visto que em 2011 iniciou com a oferta de dois cursos e em 2019 já estava ofertando um total de cinco cursos de licenciatura na modalidade presencial. É oportuno mencionar que desde o final de 2018, o IFAP por meio da Universidade Aberta do Brasil (UAB), oferta o curso de licenciatura em pedagogia à distância, contemplando matriculas em todos os seus campi, que atuam como polo presencial para dar suporte educacional aos estudantes.

É importante ressaltar que o crescimento evidenciado no campus Macapá está relacionado ao fato de o mesmo ser localizado na 
capital do Estado, onde a concentração de habitantes e as exigências por mão de obra qualificada para atender as demandas locais são relativamente maiores em comparação com os demais municípios do Estado. Destaca-se também que Macapá é uma cidade que possui atualmente mais de 500 mil habitantes, segundo dados do IBGE e tem na área de serviços a maior representatividade do PIB Amapaense, sendo o serviço público a atividade de maior destaque. $O$ Estado do Amapá possui aproximadamente $846^{4}$ escolas de Ensino Fundamental e Médio, sendo Macapá o município que possui o maior número: 316 escolas e cerca de aproximadamente 4977 professores contratados (efetivos e temporários), situação que favorece $o$ interesse pelas matrículas em cursos de licenciatura, dada a possibilidade de inserção no mercado de trabalho.

Nossa pesquisa foi realizada nos documentos oficiais norteadores dos Cursos: Plano de desenvolvimento Institucional e Projetos Pedagógicos, a fim de identificar elementos que indicassem a organização curricular, proposta político pedagógica e concepção filosófica nos quais os cursos de licenciatura do IFAP estão assentados. Essa etapa da investigação também permitiu conhecer o perfil de professores que o IFAP pretende formar e quais os aspectos diferenciais e desafios da formação ofertada pela Instituição.

Quanto a Organização curricular, os cursos de licenciatura estão estruturados em disciplinas semestrais, com duração mínima de quatro anos e possuem carga horária mínima de 3.200 horas, conforme determina a Resolução CNE/CP no 2/2015. O desenho curricular é dividido em 3 Núcleos Formativos: Núcleo Específico, Núcleo Complementar e Núcleo Pedagógico, além do Estágio Supervisionado, Atividades Complementares e trabalho de conclusão de curso. Essa divisão em três Núcleos Formativos se aproxima das orientações propostas pela Secretaria de Educação Profissional e Tecnológica (SETEC/MEC) para os Cursos de licenciatura ofertados na Rede Federal de Educação Profissional e Tecnológica, presentes no texto "contribuições para o processo de construção dos cursos de licenciatura dos Institutos Federais de Educação, Ciência $e$ Tecnologia" (BRASIL, 2011, p.13).

\footnotetext{
${ }^{4}$ IBGE - Instituto Brasileiro de Geografia e Estatística: Dados extraídos do portal https://cidades.ibge.gov.br/brasil/ap/macapa/panorama
}

No desenho curricular apresentado pela SETEC/MEC, propõe um modelo de licenciatura que articule conhecimentos práticos aos conhecimentos teóricos, ressaltando o uso de "projetos integradores interdisciplinares, delineados com uma base curricular comum às áreas de conhecimento e com forte embasamento na práxis associada à Educação Profissional" (BRASIL, 2011, p.4). A articulação de saberes na formação do licenciado tem o intuito de contribuir para superação do padrão tradicional representado pelo fragmentado esquema $3+1$, que historicamente acompanhou a constituição dos cursos de licenciatura.

Nesse modelo de formação, estudavamse nos três primeiros anos as disciplinas específicas e no último ano, as disciplinas para a formação didática. Saviani (2009) reverbera que a previsão legal para formação de professores em nível superior foi contemplada somente na década de 1970, com o advento da lei $n$. $5.692 / 71$, que previu a oferta de cursos de licenciatura curta ( 3 anos de duração) ou plena (4 anos de duração), ainda ancorados fortemente no viés da racionalidade técnica, peculiar ao modelo $3+1$.

Ao se analisar a concepção de formação e o perfil profissional do egresso do IFAP expressos nos documentos norteadores dos cursos, verificaram-se na divisão da matriz curricular, o predomínio de carga horária para componentes curriculares do núcleo de formação específica (conhecimentos da área técnica) e uma quantidade de carga horária consideravelmente inferior destinada ao núcleo pedagógico (conhecimentos pedagógicos), sugerindo o pouco prestígio atribuído aos conhecimentos didáticos pedagógicos.

Segundo Gatti (2014), no Brasil, os currículos dos cursos de licenciatura ainda segregam a área do conhecimento específico da área dos conhecimentos pedagógicos, dedicando pequena parte de seu currículo às práticas profissionais relativas à docência. Para a autora, isso acarreta em uma série de prejuízos à formação dos futuros formadores, denotando inclusive a pouca preocupação das IES com esses cursos e sua vocação precípua, uma vez que coloca em segundo plano a reflexão acerca da docência e das múltiplas dimensões que envolvem o fazer docente, o qual é o cerne dos cursos de licenciatura.

De acordo com o PDI da Instituição, o IFAP atua dentro de uma proposta formativa que 
propicie ao estudante uma "formação crítica, humana e contextualizada, cercada de conhecimentos, princípios e valores que potencializam a ação do ser humano na busca de caminhos de vida mais digna". Pelo fragmento retirado do documento norteador oficial da Instituição, é possível afirmar que o IFAP se inclina favoravelmente ao desenvolvimento de práticas educativas contextualizadas que estimulem a capacidade crítico/reflexiva do sujeito, tendo em vista sua emancipação humana e a transformação social.

Considerando tais inclinações, procurouse conhecer qual a concepção de homem e de sociedade entendida pela Instituição, que segundo o próprio PDI, considera:

[...] o ser humano entendido como um "ser histórico-social que atua no mundo concreto de forma consciente para projetar e satisfazer suas necessidades subjetivas e sociais, construindo e reconstruindo

conhecimentos.

[...] a sociedade é aquela na qual se acredita ser fruto de uma construção humana em âmbito coletivo, que se estrutura ao longo de gerações, reorganizando seus conceitos e paradigmas na medida em que acontece o desenvolvimento físico e intelectual dos sujeitos, estabelecendo relações coletivas em busca da satisfação das necessidades intrínsecas do ser humano. (PDI/IFAP, 2019-2023, p. 109).

Portanto, o conceito de homem e de sociedade contido no PDI-IFAP encontra-se fundamentado no pensamento gramsciano, ao reconhecer o homem como "espírito, isto é, criação histórica e não natural" (GRAMSCI, 1972, p.24), ou seja, como sujeito de sua história e do seu papel ativo no processo de transformação da realidade social. Para o autor, a escola se constitui enquanto espaço privilegiado para formação integral do indivíduo, ao assumir o compromisso social de difundir o conhecimento científico historicamente acumulado a todos os indivíduos, independentemente de cor, classe social e/ou mero interesse por qualificação de mão de obra.

Contudo, Gatti (2014) chama a atenção para o idealismo perceptível nas proposições dos projetos pedagógicos dos cursos de licenciatura, revelando que nem sempre as ideias se concretizam na formação realmente ofertada, ao passo que teorias e práticas não se mostram integradas. Exemplo disso pode ser notado no descompasso que há entre as finalidades educativas expressas no PDI-IFAP e a distribuição desigual das cargas horárias nas matrizes curriculares dos cursos, as quais privilegiam os conteúdos da formação técnica e que se alicerçam no viés da instrumentalização do trabalho para o mercado, deixando em segundo plano a formação humana.

Em relação às entrevistas que realizamos com alunos, professores e gestores pedagógicos atuantes nos cursos de licenciatura do IFAP, as mesmas tiveram o propósito de identificar as potencialidades e desafios da formação ofertada pela instituição. Para efeitos de diagnóstico, as potencialidades foram tratadas como pontos positivos e os desafios como pontos a serem melhorados, tendo em vista a qualidade da formação dos estudantes. Para tanto, os participantes foram inquiridos com um questionamento comum a todos: "Na sua opinião, quais as potencialidades e desafios da formação nos cursos de licenciatura do IFAP?"

Quanto às potencialidades (pontos positivos) da formação ofertada pela instituição, os aspectos mais destacados foram: infraestrutura preservada, professores qualificados, auxílios de assistência estudantil e bolsas relativas ao Programa Institucional de Iniciação à Docência (PIBID), Programa Institucional de Bolsa de Iniciação Científica (PIBIC) e Residência Pedagógica. Ressalta -se que, de acordo com os depoimentos dos participantes, a possibilidade de participação em bolsas e auxílios é um fator que gera grande motivação nos estudantes, principalmente naqueles que possuem condições socioeconômicas desfavoráveis. O depoimento de um dos alunos entrevistados ilustra a importância de tais oportunidades.

Aluno (A- 3) - A assistência aos alunos, através das bolsas e dos auxílios é um dos pontos positivos do IFAP, porque ajuda o aluno a permanecer e se manter 
no curso. Muitos alunos carentes não conseguem nem chegar à instituição por não terem condições de pagar o transporte público, então os auxílios e as bolsas do programa de formação e do programa de monitoria são fundamentais para a conclusão dos estudos

As experiências positivas com os Programas PIBID e Residência Pedagógica foram enfatizadas nas falas de alunos e professores, visto que proporcionam aos estudantes das licenciaturas uma vivência no seu campo de atuação profissional. No PIBID, essa experiência acontece desde os semestres iniciais da formação acadêmica e no Programa Residência pedagógica, por sua vez, a inserção do licenciando na escola de educação básica acontece a partir da segunda metade de seu curso. Ambos os programas têm como finalidade $o$ aperfeiçoamento e a valorização da formação de professores a partir da imersão dos estudantes no contexto das escolas públicas, a fim de que os mesmos desenvolvam habilidades e competências que Ihes permitam realizar um ensino de qualidade nas escolas de educação básica.

Gatti et al. (2014) avaliam o PIBID de forma positiva e consideram abrangentes as contribuições do Programa, tanta na qualidade de política pública, pois fornece elementos para o fortalecimento de suas ações, quanto para os estudantes - bolsistas, pois além de proporciona contato com a escola pública, no início de seu curso. Permite a aproximação mais consistente entre teoria e prática, estimula a iniciativa e a criatividade, incentivando-os a buscar soluções, planejar e desenvolver atividades de ensino e a construir diferentes materiais didáticos e pedagógicos. Proporcionando formação mais qualificada dos Licenciandos. (GATTI et al. 2014).

$O$ relato do aluno, a seguir, confirma a importância dos Programas de incentivo ao aperfeiçoamento da formação prática nos cursos de licenciatura:

Aluno (A-5)
programas Considero os
Residência $\quad$ pedagógica
pontos positivos na
formação ofertada nos
Cursos de Licenciatura do
IFAP, pois ajudam muito na

formação do licenciado. Através deles, temos contato com a realidade escolar antes de chegar na etapa do estágio e, além disso, ainda ganhamos uma bolsa que nos ajudar a continuar o curso. Desde o segundo semestre do meu Curso, eu entrei no PIBID e as experiências que adquiri nele facilitaram minha decisão em ser professor e quando chegou à etapa do estágio não tive dificuldades, pois já conhecia bem a realidade do meu futuro ambiente de trabalho.

No ano de 2019, o IFAP disponibilizou 52 (cinquenta e duas) bolsas PIBID e 72 (setenta e duas) bolsas do Programa Residência Pedagógica distribuídas entre os estudantes dos Cursos de Licenciatura da instituição. Esse quantitativo de bolsas é relativamente pequeno se comparado aos 819 alunos matriculados nos 6 cursos de licenciatura no referido ano, impossibilitando a participação mais expressiva de alunos nesses Programas. Contudo, os alunos não contemplados podem concorrer à seleção de bolsas do PIBIC e dos demais auxílios proporcionados pelo Instituto.

No tocante aos desafios da formação de professores no IFAP, os participantes alunos destacaram, dentre outros aspectos: atualização do acervo bibliográfico, construção de um laboratório específico para práticas de ensino, ausência da formação pedagógica de alguns professores e pouca atenção destinada aos Cursos Superiores da Instituição.

Quanto à questão da ausência da formação pedagógica dos professores, Guedes e Sanchez (2017) salientam que a maioria dos professores do IFAP que possuem maior grau de titulação acadêmica (mestrado e doutorado) pertencem a área técnica, e essa condição "faz com que alguns desses professores não considerem importante e produtivo a formação pedagógica através de cursos que venham complementar a sua prática em sala de aula". (GUEDES; SANCHEZ, 2017, p. 245). Ressalta-se que o IFAP preocupado com essa situação, promove cursos e ações que visam a contribuir para erradicar tal problema. A instituição também 
tem exigido nos editais de seleção de professores efetivos, a formação pedagógica (licenciatura ou complementação).

0 relato de (A-1) mostra que esse fator é prejudicial à formação dos alunos, visto que são cursos cuja finalidade é a formação para atuação docente e os alunos desses cursos buscam em seus professores o exemplo e referência profissional.

Aluno (A-1) - O IFAP tem um quadro de professores com excelente formação acadêmica, mas é visível em muitos professores da área especifica do curso, a fragilidade na formação pedagógica. Isso reflete diretamente na formação dos alunos, pois, por não possuírem domínio de metodologias de ensino e da didática, acabam ministrando aulas com pouca qualidade e induzindo o aluno a agir semelhante a ele e isso é mais comum de se ver nos professores com pouca experiência de docência. Esse é um ponto que o IFAP precisa melhorar.

Um aspecto bastante enfatizado pelos alunos diz respeito à pouca atenção destinada ao Ensino Superior dentro da instituição, isso resgata a reflexão acerca das finalidades e diretrizes dos Institutos Federais preconizadas na Lei $\mathrm{n}$. o 11.892, que estabelece em termos quantitativos a oferta de vagas mais significativa para o ensino profissionalizante. Nesses termos, os cursos superiores tem pouca visibilidade, por ocuparem menor lugar de destaque em comparação aos Cursos Técnicos, ocasionando uma sensação de desprestigiados e até mesmo de excluídos pela Instituição, conforme depoimento do aluno (A-7):

Aluno (A -7) - O ensino
superior do IFAP não é
valorizado diante dos
outros segmentos,
especialmente dos cursos
técnicos que visivelmente
são privilegiados pela
Instituição, pois quando
têm eventos e editais, as
informações não chegam
até os Cursos superiores e,

por conta disso, os alunos acabam ficando de fora.

No campus Macapá não há um departamento específico para o Ensino Superior como ocorre em grande parte das universidades; o que existe são as coordenações de cursos ligadas à Direção de ensino do campus. Os docentes aprovados nos concursos ou contratados temporariamente são alocados de acordo com a demanda dos cursos, ou seja, é a demanda que determina o curso em que o docente atuará, podendo ser no Ensino Médio Profissionalizante, Superior e até na PósGraduação. Infere-se que a falta de um departamento específico para o Ensino Superior e de professores efetivamente ligados aos cursos compromete o processo de construção da identidade dessas licenciaturas na instituição, visto que dificulta as tomadas de decisões necessárias às melhorias da formação nos cursos.

Já na visão dos professores entrevistados, os pontos de maior destaque e que necessitam de aprimoramento na Instituição são, dentre outros, os seguintes: 1. A criação de um laboratório pedagógico de práticas de ensino, que também corresponde a um anseio enfatizado nas falas dos alunos e que se traduzirá em um espaço onde os estudantes das licenciaturas terão oportunidades de terem contato com recursos e ferramentas didático-pedagógicas para auxilia-los na construção das aulas de regência de classe e nas oficinas pedagógicas. 2. A verticalização do ensino, cujo tipo de organização é uma característica marcante dos Institutos Federais e que se trata de um aspecto que, na opinião dos professores investigados, precisa ser amplamente debatido em âmbito institucional, por representar um grande desafio na organização do docente nos IFs. Conforme pode ser visto no depoimento do docente a seguir:

Docente (D-2) - O fato de o professor atuar em diferentes níveis num mesmo período é um fator que, ao mesmo tempo que contribui para a experiência da prática docente do professor, também traz prejuízos, pois, além de ser cansativo, devido à elevada carga horária de aulas, confunde a cabeça. Pois, o professor, nos dois 
primeiros horários, está no Curso Técnico (Ensino Médio) e, em seguida, entra no Curso de Licenciatura (Ensino Superior) e isso atrapalha nossa prática muitas vezes, visto que são níveis de ensino e públicos diferentes.

Sabe-se que a atuação dos professores dos IFs tem um caráter diferenciado se comparados aos das universidades, uma vez que é da "natureza dos institutos federais validar a verticalização do ensino e balizar as suas políticas de atuação pela oferta de diferentes níveis e modalidades da educação profissional e tecnológica, básica e superior" (PACHECO, 2011, p. 23). Isso pressupõe que as condições de trabalho desses profissionais no âmbito das licenciaturas podem indicar outros modos de construção desses cursos. O depoimento do gestor a seguir, analisa a questão da verticalização dos IFs como um aspecto positivo e como o maior diferencial na formação dos estudantes, se comparado com a formação ofertada pelas Universidades, pois, segundo ele:

Gestor (G-2): [...] enquanto $\mathrm{O}$ Professor universitário se prende em questões academicistas e por conta disso se limita a formar o estudante com base em vivências centradas na Educação Superior, o docente EBTT, que atua dentro de uma estrutura verticalizada proporcionada pelos Institutos Federais, tem a possibilidade de oferecer ao aluno uma diversidade de vivência de outros níveis e modalidades de ensino $e$, inclusive, possibilitar uma integração entre os alunos dos diferentes segmentos formativos da Instituição e, assim, contribuir significativamente para a formação dos estudantes, em especial, dos estudantes dos Cursos de Licenciatura que irão atuar na Educação básica e que necessitam

dessas

contribuições para a

formação dos mesmos.

Dentro dessa discussão, caberia mencionar que aos Institutos Federais está posto, por determinação legal, o desafio de atuar em diferentes níveis de ensino, o que implica um vasto campo de atuação e, ao mesmo tempo, a superação de uma série de entraves e resistências frente a essa configuração institucional, que tem como uma das suas finalidades a promoção da "[...] integração e a verticalização da educação básica à educação profissional e educação superior, otimizando a infraestrutura física, os quadros de pessoal e os recursos de gestão" (BRASIL, 2008).

Desta forma, percebe-se que os anseios e desafios apresentados pelos docentes do IFAP acerca da estrutura de ensino verticalizada e os reflexos sobre as práticas docentes são questões que requerem atenção para que se possa desenvolver uma prática pedagógica coerente com os objetivos institucionais propostos e alinhados aos princípios da verticalização, a fim de buscar uma atuação significativa nos cursos de licenciatura dentro do contexto dos IFs, de modo a atender ao compromisso social que justifica a criação dessas Instituições.

\section{CONSIDERAÇÕES FINAIS}

A lei 11.892/2008 atribuiu aos Institutos Federais a responsabilidade da oferta de cursos de licenciatura e, como forma de assegurar esta premissa, foi estabelecido o quantitativo de pelo menos $20 \%$ (vinte por cento) das matriculas/vagas para a formação de professores. Tal incentivo governamental, decorre de uma necessidade histórica relacionada à carência de professores no País, especialmente nas disciplinas de Física, Química, Biologia e Matemática. No Estado do Amapá, o IFAP desempenha uma importante participação na expansão dos cursos de formação de professores, ofertando seis cursos presenciais de licenciaturas em 2 campi (campus Macapá e campus Laranjal do Jari).

Os dados da pesquisa evidenciaram que a participação do IFAP no cenário educacional amapaense encontra-se em crescente ascensão. Visto que em 2011, a Instituição tinha apenas 3 turmas/cursos de licenciatura, ofertados no período noturno e, em 2019, esse quantitativo elevou-se para 17 turmas, com o total geral de 819 alunos matriculados nos 3 turnos (matutino, 
vespertino e noturno). Isso demonstra que a inserção das licenciaturas nos IFs está para além de uma simples medida compensatória voltada para superação do déficit de docentes, uma vez que estas instituições vêm se consolidando como um novo lócus de formação de professores em promissora expansão, apesar de todos desafios estruturais e os de natureza intrínseca existentes na história da Rede Federal de Educação Profissional.

Por conseguinte, é preciso considerar que tradicionalmente os IFs atuam com o Ensino Técnico profissionalizante e não tem o Ensino Superior e a formação de professores como foco de atuação principal. O que contribui para suscitar questionamentos sobre uma possível

\section{REFERÊNCIAS}

BRASIL. Lei no 11.892, de 29 de dezembro de 2008. Institui a Rede Federal de Educação Profissional, Científica e Tecnológica, cria os Institutos Federais de Educação, Ciência e Tecnologia, e dá outras providências. Brasília, 2008.

BRASIL. Ministério da Educação. Contribuições para o processo de construção dos cursos de licenciatura dos institutos federais de educação, ciência e tecnologia. (documento técnico encaminhado à SETEC/MEC). Brasília: MEC/SETE C, 2008.

GATTI, B. A. Formação inicial de professores para a Educação básica: pesquisas e políticas educacionais. Estudos em Avaliação Educacional, São Paulo, v. 25, n. 57, p. 24-54, jan./abr. 2014. Disponível em: http://publicacoes.fcc.org.br/ojs/index.php/eae/a rticle/view/2823. Acesso em: 15 set. 2019. DOI: 10.18222/eae255720142823

GATTI, B. A. Educação, escola e formação de professores: políticas e impasses. Educar em Revista, Curitiba, Brasil, n. 50, p. 51-67, out./dez. 2013. Editora UFPR. Disponível em: https://www.scielo.br/scielo.php?script=sci artte xt\&pid=S0104-

$40602013000400005 \& \operatorname{lng}=p t \& t \mid n g=p t . \quad$ Acesso em: 15 set. 2019. DOI: 10.1590/S0104$\underline{40602013000400005}$ fragilidade na formação desenvolvida nos cursos de licenciatura ofertados nessas instituições de ensino. Contudo, a característica pluricurricular dos IFs possibilita o diálogo pedagógico entre diferentes níveis e modalidades, favorecendo o enriquecimento mútuo no processo formativo tanto nos cursos de formação docente, quanto nos demais cursos envolvidos.

Finalmente, consideramos relevante a ampliação dos debates e estudos sobre a expansão das licenciaturas nos Institutos Federais, dada a necessidade de conhecer os progressos, limitações e singularidades da formação docente desenvolvida no âmbito dessas instituições.

GATTI, B et al. Um estudo avaliativo do Programa Institucional de Bolsa de Iniciação à docência (Pibid). São Paulo: FCC/SEP, 2014.

GUEDES, I. A. C.; SANCHEZ, L. B. A formação docente para a Educação Profissional Técnica e sua influência na atuação dos professores do Instituto Federal do Amapá - campus Macapá: Um estudo de caso. Revista HOLOS, Natal, v. 33, n. 7, p. 238-250, 2017. Disponível em: http://www2.ifrn.edu.br/ojs/index.php/HOLOS/a rticle/view/6093/pdf. Acesso em: 15 set. 2019.

LIMA, F. B. G. de. Os Institutos Federais como um novo lócus de Formação de professores. Movimento - Revista de Educação, v. 3, p. 297 324, $2016 . \quad$ Disponível em: https://periodicos.uff.br/index/index. Acesso em: 15 set. 2019.2 DOI: 10.22409/movimento2016.v0i4.a20919

LIMA, F. B. G.; SILVA, K. A. C. P. Cordeiro da. As licenciaturas nos Institutos Federais: concepções e pressupostos. In: ENCONTRO ESTADUAL DE DIDÁTICA E PRÁTICA DE ENSINO, 4, 2011, Goiânia. Anais do IV Encontro Estadual de Didática e Prática de Ensino. Goiânia, 2011. Disponível em: http://www.ceped.ueg.br/anais/ivedipe/pdfs/did atica/co/40-164-2-SP.pdf. Acesso em: 20 out. 2018.

MACHADO, L. R. S. Diferenciais inovadores na formação de professores para educação profissional. (documento técnico encaminhado à SETEC/MEC). Brasília: MEC/SETEC, 2008. 
MANCEBO, D.; SILVA Jr., J. R. Expansão da educação superior e a reforma da rede federal de educação profissional. Revista Educação em Questão, Natal, v. 51, n. 37, p. 73-94, jan./abr. 2015. Disponível em: https://periodicos.ufrn.br/educacaoemquestao/a rticle/view/7172. Acesso em: 15 set. 2019. DOI: 10.21680/1981-1802.2015v51n37ID7172

NEVES, C. E. B. Diversificação do Sistema de Educação Terciária: um desafio para o Brasil. Tempo Social, São Paulo, v. 15, n.1, p.21-44, abr. $2003 . \quad$ Disponível em: https://www.scielo.br/scielo.php?script=sci artte xt\&pid=S0103-

20702003000100002\&lng=pt\&nrm=iso\&tlng=pt. https://doi.org/10.1590/S0103-

20702003000100002. Acesso em: 15 set. 2019.

OTRANTO, C. R. A Reforma da Educação Profissional e seus reflexos na Educação Superior. Revista Temas em Educação, João Pessoa, v. 22, n. 2, p. 122-135, jul./dez. 2013.

SGUISSARDI, V. Modelo de expansão da educação superior no Brasil: predomínio privado/mercantil e desafios para a regulação e a formação universitária. Educação e Sociedade, Campinas, v. 29, n. 105, p. 991-1022, dez. 2008. Disponível em: http://www.scielo.br/pdf/es/v29n105/v29n105a 04.pdf. Acesso em: 15 set. 2019. DOI: 10.1590/S0101-73302008000400004

SAVIANI, D. Formação de Professores: aspectos históricos e teóricos do problema no contexto brasileiro. Revista Brasileira de Educação, Rio de Janeiro, v. 14, n. 40, p. 143-155, jan./abr., 2009. Disponível em: https://www.scielo.br/scielo.php?script=sci artte xt\&pid=S1413-

24782009000100012\&lng=pt\&tlng=pt. Acesso em: 15 set. 2019. DOI: 10.1590/S1413$\underline{24782009000100012}$

TANURI, L. M. História da formação de professores. Revista Brasileira de Educação, Rio de Janeiro, n. 14, p. 61-88, mai./ago., 2000. 